\title{
Natural and political markets organizing the transfer of technology and knowledge
}

Tryggestad, Kjell

Document Version

Final published version

Publication date:

2002

License

CC BY-NC-ND

Citation for published version (APA):

Tryggestad, K. (2002). Natural and political markets: organizing the transfer of technology and knowledge.

Link to publication in CBS Research Portal

\section{General rights}

Copyright and moral rights for the publications made accessible in the public portal are retained by the authors and/or other copyright owners and it is a condition of accessing publications that users recognise and abide by the legal requirements associated with these rights.

Take down policy

If you believe that this document breaches copyright please contact us (research.lib@cbs.dk) providing details, and we will remove access to the work immediately and investigate your claim. 


\section{Working Paper}

No. 2003.24

Kjell Tryggestad

NATURAL AND POLITICAL MARKETS ORGANIZING THE TRANSFER OF TECHNOLOGY AND KNOWLEDGE

INSTITUT FOR ORGANISATION OG ARBEJDSSOCIOLOGI Handelshøjskolen i København

Solbjerg Plads 3

2000 Frederiksberg

TIf: $38152815 \quad$ Fax: 38152828 


\title{
NATURAL AND POLITICAL MARKETS - ORGANIZING THE TRANSFER OF TECHNOLOGY AND KNOWLEDGE
}

Paper to be presented at EGOS subtheme 23: Markets-in-the-Making, Copenhagen 3-5 July 2003

\author{
Kjell Tryggestad
}

Copenhagen Business School

Department of Organization and Industrial Sociology

\begin{abstract}
The aim of this work is to conduct a theoretical and empirical investigation of how the market institution performs in the context of technology and knowledge transfer. The notion of political markets, first introduced by Adam Smith, is extended to the artifacts of technology and their associated factor markets. The paper develops the notion of political markets by drawing upon an empirical case that reconstructs the chain of events related to the transfer of flexible manufacturing systems (FMS). The case account for the various actors and institutions involved in the technology transfer, including the firms on both sides of the market, the government, the engineering-scientists, the economists, the union representatives and the machinists.
\end{abstract}

It is argued that Natural markets is a special case of political markets in which technologies and hybrid entities and identities produce both the Natural market as well as its master - the pure technological relations. Neither the Natural market, nor Homo economicus can be brought into existence without pure technological relations. The existence of the latter is a necessary condition for the existence of the two former, as has already been recognized by neoclassical economics. The present work makes a constructive contribution to neoclassical economics in this respect, by describing and analyzing all the work of purification that enters into the task of bringing the necessary conditions into existence. Indeed, the process of purification that brings purified 
technologies, natural markets and rational identities like homo economicus into existence, require huge investments, as do their maintenance. Technical knowledge turned out to be no exception. As the case suggests, technical knowledge was not just a given condition, but became a produced outcome. Yet, the process of knowledge production continued, transforming given technical knowledge in unexpected ways. Technical knowledge also became a negotiated outcome during the transfer of FMS. Hence, when market transaction takes place, knowledge it self can be transformed, and with it, the conditions for conducting the market transaction. So, the notion of political markets proposed here, suggests that knowledge can be both premises as well as an outcome of market transaction - as knowledge, its status and distribution - can be negotiated in the process. Instead of criticizing Homo economicus and (neo) classical economics, the notion of political markets thus proposed imply a constructive contribution to economics, notably to the core of neo classical economics:

Through out this paper, it is argued with reference to both theory and own empirical fieldwork, that neoclassical economics participate in the successful purification of technological relations. Yet, in order to provide for an explanation of such a successful outcome, it is not enough to account for economists among themselves. As has already been suggested by Callon (1998) and the associated work on the anthropology of markets, also such material associations as computer based calculations and simulations of the macro-economy must be brought into the explanation. In more specific terms, the puzzling 'residual' in the neoclassical production function can be explained by now also taking into account the many subtle ways economics itself interfere in making up the residual. Neoclassical economics only have to refine their production function by adding to it the significance of material associations such as computer based calculations and simulations of the macro-economy. Done properly, a revised macro-economic model would emerge, capable of handling 'market failures' in new ways. Instead of attributing all failures to the market and no failures to technology, a more symmetric distribution of failures between the two entities would be allowed for. Further more, each time a 'residual' emerges from applying the revised model, it is no longer simply due to 'technical change' but also due to 'market failures'. Hence, such a revised macro-economic model not only allow neoclassical economics to maintain the distinction between technology and the market but also allows for the flexibility of including those entities previously excluded, that is, the material associations and inscriptions that participates in making up the distinctions between the two. 


\section{INTRODUCTION}

In "The Wealth of Nations", Adam Smith (1776/1986) described a labor market populated with "masters" and "servants". In the author's account, the distribution of the two identities and their associated interests were organized according to their specific location in the employment contract. The employers were identified as the masters, and the workmen as their servants, since " The masters, being fewer in number, can combine much more easily; and the law, besides, authorises, or at least does not prohibits their combinations, while it prohibits those of the workmen. We have no acts of parliament against combining to lower the price of work; but many against combining to raise it. ...whoever imagines upon this account, that masters rarely combine, is as ignorant of the world as of the subject" (Ibid., p.169). On these pages, Adam Smith describes in rich detail the propensity to organize and negotiate the price of work between the two parties. The author also gives an interesting explanation of the asymmetries involved in that process: the employers are fewer and can combine more efficiently; they have the financial means so as to endure much longer in a conflict. In addition, they have the institutions of society, the parliament and the law, on their side. All this adds up to make employers the masters, and the workmen their servants, and - Adam Smith's work a most classical contribution to political economics. For some reason or another, Adam Smith never extended his theory of political markets to that of the other factor market, i.e., the machinery and materials of production.

Smith also restricted his inquiry of identities and their distribution to the realm of humans. The present author would like to not only extend Smith's inquiry, but also qualify it so as to include the possible significance of the materials and artifacts of technology in the production of the various identities. As described by Kreiner and Tryggestad (2002), our study of computer-based design of integrated circuits suggested that technologies might be servants in the hands of human masters, but that such roles also may be redistributed through the course of events. In this respect, the present author also share concerns with recent work into the anthropology of science, technology and organizational identities. Czarniawska (2000) has urged those social scientists interested in the question of human and organizational identities to pay some more attention to the artifacts of technology. She argues that identities like 'humanity' can emerge in interaction with the artifacts of technology. In his anthropology of markets, Callon (1998a) argues that such rational calculative entities like homo economicus can be produced in interaction with materials and artifacts of 
technology, notably those that perform calculations of various kinds According to the author, economists "performs, shapes and formats the economy, rather than observing how it functions" (Ibid.,p.2). Economists and their associated calculative technologies are thus brought into an explanation of an emergent homo economicus. Here, it should be emphasized that the anthropology of markets allows material entities and associated inscriptions to play a central role in performing calculations and in formatting the economy " The material reality of calculation, involving figures, writing mediums and inscriptions... are decisive in performing calculations.” (Ibid, pp.4-5) ${ }^{1}$. Law (1987/1990), argues that the social in made from an interacting network of heterogeneous elements consisting of both humans and artifacts. The social is thus an outcome of "heterogeneous engineering'. Much in the same vein as Callon and Law above, Latour (1994) argues that modern sociologists and economists belief in a 'macro' (or 'global') level harboring a decontextualized rationality should be seen as an outcome of a work of purification. In such modern accounts, the universal rationality of the soulless bureaucracy or the pure and perfect marketplace ('macro') is taken to belong to a different ontological realm than that of 'micro'. Through the work of purification, the network making 'micro', 'macro' and their linkages, are made invisible. The two entities thus become separated- as if made from different substances, the author argues. The coedited anthology 'Translating Organizational Change' (Czarniawska and Sevón, 1996) extends this line of argumentation to the field of organizational theory.

The question of rationality, its status and distribution, is certainly not new to the social sciences. Economic inclined journals such as 'Rationality and Society' participate in its institutionalization, perhaps also extending universal rationality to new horizons. There are other options. Within the field of economics and organizational theory, Augier and Kreiner (2000) provide an interesting historical account of rationality, notably the different versions of 'bounded rationality' as formulated by Herbert Simon, George Shackle and James G. March. Following March (1994), the authors argue that 'rationality' is a concept that has many meanings and is used in different ways (Ibid., p.660). In the following, this line of argumentation will be explored by adding to the many possible uses of 'rationality' also the production of the different rationalities. By emphasizing such a production perspective ( Kreiner and Tryggestad, 2002), the debate concerning 'rationality' can perhaps be recontextualized: 
In the debate, words such as 'homo economicus' and 'homo sociologicus' are used for various purposes - sometimes as a way to describe and summarize the different positions, but the effect is often one of polarization. To take an example, " The most basic difference between economics and sociology concerns their assumptions about human nature. The famous homo economicus is a rational, self-interested, instrumental maximizer with fixed preferences. Homo sociologicus, by contrast, is much harder to define...Actions follows from culturally given values, not just some pure (culture-free) calculation of individual self-interest." (Hirsch, Michaels and Friedman, 1990, pp.4244).

The rationality of 'homo economicus' as well as that of 'homo sociologicus' is, as the word says, 'assumptions' or foundations for doing neoclassical economics and economic sociology respectively. It is suggested here that the question of rationality should not simply be regarded as a foundation or premises for doing social science. Entities such as 'homo economicus' and 'homo sociologicus' can perhaps be two of many possibly produced outcomes rather than just premises for doing social science. Rather than being concerned with a given distribution, that is, rationality as either distributed to the individual human ('homo economicus') or distributed to a collective of humans ('homo sociologicus'), a perspective emphasizing the production allows the researcher to pose the question of how different rationalities are produced and re-distributed through the course of events.

In addition to the question of the status and distribution of rationality, this work also share concerns with neoclassical economics and economic sociology regarding the market. I will try to qualify the question of how the different rationalities can be produced and re-distributed while linking it to the concerns with the market: The 'market', Zukin and DiMaggio (1990) argue is the entity neoclassical economists turn to, when confronted with behavioral theorists and sociologists that questions the existence of a 'homo economicus'. "The classical response of economic orthodoxy is on a "higher level": the invisible hand of the market will reward efficient firms..." (p.7). The authors claim a "crisis" (p.6) in the theory of the firm ${ }^{2}$. But then again, neither the new economic sociologists, nor neo-classical economists investigate the production of 'homo economicus', or in the words of Callon (1998) "Both carefully avoid the only question worth posing: how can the emergence and formatting of calculative agencies be explained?" (Ibid., p.51). 
As a possible extension of Callon's important point, I would like to emphasize that the neoclassical economists, like Adam Smith before them, have recognized the existence of production technologies, but only to devote much effort in making them and their associated markets part of a non-political nature. The new economic sociologists have treated markets as part of their discipline, but are rather silent about the possible relevance of the machines and other materials of technology for their economic sociology. Hence, the aim of this paper is to inquire into the possible existence and significance of production technologies and their markets in the production of emerging identities like 'homo economicus. What are these markets made of? Can they be both natural and political? Perhaps the markets for production technologies are made up by such diverse identities like masters and servants.

There are many possible points of entry for an inquiry into such questions. The one preferred in the present work is the theory of the firm, or more specifically, the neoclassical production function. As will be argued in the following (section two), a closer attention to the production function can be rewarding if one wants to inquire into the production of such calculative agencies as homo economicus. In section three, I will extend the inquiry of the production and distribution of "homo economicus' to the practicians out in the field. In the concluding section (four) some possible implications for theory and practice will be discussed.

\section{THE PRODUCTION OF THE NEO-CLASSICAL PRODUCTION FUNCTION - BRINGING HOMO ECONOMICUS INTO EXISTENCE}

\subsection{Constructing pure technological relations - producing the Other production function, solving} the problem of technical maximization

The production function occupy a central place in the theory of the firm as well as in economics, perhaps to the extent of defining the identity of being an economist proper: "There can be little doubt that the production function, and their associated cost functions, form an integral part of an enormous range of economic theory. In microeconomics, production functions underlies the supply side of markets, generate production possibility frontiers, offer an explanation of income distribution and yield factor demand functions. Production functions are also central to the theory of economic growth and to investigations into the rate of technological progress... The functional 
forms used for utility functions are often 'borrowed' from production theory [etc.]...It is clear from this somewhat impressive list that knowledge of production functions is a useful if not essential part of being an economist"(Heathfield and Wibe, 1987, p.ix).

Before entering the subtleties of the production function, by neoclassical standards, the "hard-core" (Chung, 1994, p.xi) areas of economics, the present author would like to give credits to economists for all the work put into the effort of clarifying the relationship between technology and the economic world. That list would include work from such eminent mathematicians and economists such as Cobb and Douglas (1928) and the associated, perhaps first mathematically formalized, 'well behaved' neoclassical Cobb-Douglas production function in which a lower wage rate is associated with a more labor-intensive technique, Sheppard's (1953/1970) 'Theory of Cost and Production Functions' and the associated Shephard's 'duality' between production functions and cost functions- the latter derived from the former and both of them describing the same production technology, Abramovitz' (1956) and the associated residual as a 'measure of our ignorance' ( $\mathrm{p}$. 11), Solow's (1957) naming of that residual as 'technical change', Salter's (1960/1966) inquiry into 'Productivity and Technical Change' and the associated problem of estimating pure production functions, Brown et al (1967) 'Theory and empirical analysis of production' and the associated controversy in estimating pure production functions, Brown's (1968) continued work 'On the theory and measurement of technological change' and the associated problem of constructing pure production functions, Samuelsson's (1980) 'Economics' and the associated neoclassical foundation of a given state of production techniques and technical knowledge, to mention but a few.

Neoclassical work on the production function generate a number of interesting research questions associated with technology and technological change, questions that also has to do with the very definition of what constitutes a proper neoclassical production function: " The production function implies that a technical maximization problem has been solved...the production function is defined such that the maximum product is obtained for each combination of factors [e.g. capital and labor]" (Brown, 1968., p.10. My emphasis). Following Samuelson (1980), the author introduce the production function under the heading "Technical Law Relating Output to Inputs: ... The theory of production begins with a specific engineering or technological information...The production function is the technical relationship telling the maximum amount of output capable of being 
produced by each and every set of specified inputs (or factors of production). It is defined for a given state of technical knowledge.” (Ibid., p.501. My emphasis).

Neoclassical economists such as Brown (1968) asks some of the constructivist questions the new economic sociology has yet to ask - and Samuelson (1980) for some reason or another forgot to ask while formulating the 'technical law': "Who is responsible for constructing a firm production function as we have defined it? Surely not the engineers of the firm, since they are not concerned only with inputs and outputs but with the properties of the energy sources and other factors of production...it is the economists who makes the transformation from the physical-technical properties of production to the production function he requires in his analysis." (Brown, 1968. p.10. My emphasis).

As the reader can see from Brown's interesting exposition, neoclassical economists do not run from their responsibilities, but partakes in making a clear division of labor between engineers and economists in the production of production functions. We are now beginning to get at sense of the work and effort that enters into the collective task of obtaining a neoclassical production function. In the remaining part of this section, I will try to spell out in some more detail the work that enters into the making of a neoclassical production function and what is at stake in that process:

To begin with, engineers provide the 'raw materials' so to speak, such as energy, materials, production equipment, -layout, and -logistics with their associated implications regarding production capacity and utilization, housing, and spatial localization of the afore mentioned. In contrast to engineers, economists then abstract from the many technical properties and peculiarities as defined by engineers and their "engineering production function" (Brown, 1968, p.10. My emphasis). This allows the economists to reduce the number of factors to what has become a convention of language use among neoclassical economists, i.e., "the convenient two-factor analogy"(Ibid., p.10) of capital (C) and labor (L), both made into homogeneous entities by the neoclassical economist ${ }^{3}$. What is left after this abstraction, or perhaps more to the point, 'transformation' is however not the neoclassical production function, but another production function. This other production function is neither entirely the same as the 'engineering production function', nor is it entirely the same as a neoclassical production function. So what is it then? What is going on in the production of a neoclassical production function? 
This other function is something in-between - on the way from being an 'engineering production function' to becoming a neoclassical production function. This production function has to my knowledge not yet been given a proper name. So I will now give it a name so as to remind us of it's widely neglected in-between existence. I will simply call it 'the Other production function'. So far, this Other purified function only describe the factor quantities that enters into the function so as to produce an output (even that made into an homogeneous entity by the neo-classical economist) in the most technically efficient way. It is this function that is said to have solved the technical maximization problem that the 'engineering production function' could not be entrusted with. This is also the production function which expresses a " purely technological relationship, and the economist should not embed economic variables into it [by] pre-selected the set of technical alternatives on the basis of costs." (Brown, 1968, p.4, My emphasis).

If the economist fails here, that is, embed such economic magnitudes into the construction of this Other purified production function, then it may turn into something that is hard to distinguish from the 'engineering production function' which is yet another word for a production function which can not be said to have solved the technical maximization problem: "Engineers may articulate the relations between input and outputs in physical dimensions, yet they may have pre-selected the set of technical alternatives on the basis of relative factor costs. And, in so doing, economic magnitudes creep into the production function." (Ibid., p.10). Brown's (1968) expressed concerns regarding the less pure engineering production function can perhaps best be illustrated by a simple example: If engineers starts to calculate from relative factor prices, e.g. by substituting one entity of machinery (capital goods) with one entity of labor according to their relative factor prices - instead of devoting their sole calculating efforts to obtain the combination of capital and labor that secure the maximum output, then the resulting engineering production function no longer guarantees a solution to the technical maximization problem. As such, it must be judged as less pure or unstable. As the reader will soon see, the existence of such more or less pure technological relations and production functions is a very important question in neoclassical economics for many different reasons, including the very prospect of reaching a solution to the central problem of economic optimization.

In his editorial introduction to the published papers from a major conference on production functions among the most eminent economists, Brown (1967) recognized that "SOME conferences are constructive, not in having solved any major outstanding problems, but in producing 
dissatisfaction with received knowledge..." (Ibid., p.3). And "The first substantive point of controversy of the conference arose in the connection with the use of engineering data in the estimation of production functions...criticism... holds that the production function estimates are unstable, that they depend on relative factor prices."(Ibid.,p.5. My emphasis). Yet, as Brown also emphasize, the controversy is important not only for the scientific discipline of economics as such, but also important from a practical point of view: "In itself, dissatisfaction or controversy is not sufficient to justify a conference. The problems must be important. These issues are, for not only do they lie close to the heart of production economics, they affect as well the areas of economic growth, the distribution of income and employment. The payoff of effective results would be quite substantial" (ibid. 4). Hence controversy among eminent economists was no longer just a theoretical concern associated with " the inherent difficulty of coming up with something that will satisfy scientific requirements. “(ibid., p. 4). Controversy among economists - and the associated lack of effective results, had now also become an obstacle in making the science of economics effective for policy concerns - the prospect of substantial 'payoff'.

At this conference, eminent economists like Solow, criticize the work of other eminent economists such as Kurz and Manne (1963) for producing less pure or unstable firm production functions in which economic magnitudes such as relative factor prices are embedded. This means, according to Solow (1967) that "the Kurz-Manne production function is less like an "engineering" relationship and more like a macroeconomic relation" (Ibid., p.27). Since the macroeconomic relation between inputs and outputs "are statistical aggregates...there is no possibility of finding engineering relationships. Econometric methods have to do duty instead." (ibid., p.26). Solow, by now well known for doing the macroeconomic kind of neoclassical production function, finds it to be "an intriguing idea to deduce economically useful production functions from raw technological information" (Ibid. My emphasis). Solow concludes that "very little of interest has been done on that subject" (Ibid.) - the work of Kurz and Manne being no exception. According to Solow, the repeated failures among fellow economists in estimating production functions 'from raw technological information', has paved the way for less microeconomics and more macroeconomics: "If aggregation is inevitable, relax and enjoy it"! (Ibid., p.27).

Brown (1967) summarize the controversy in connection with the use of engineering data in this way: " Though the...Solow criticisms went unchallenged at the conference - the oral remarks of Chenery, Easterlin, and Leontief could be interpreted in this way - voiced the feeling that even 
though previous efforts to estimate production functions encountered aggregation and other unresolved problems, researchers should attempt to obtain such estimates. Indeed, notwithstanding these very difficult problems, severe skeptics of the aggregate production function approach maintained that we would succeed in obtaining structural estimates of production functions only with engineering-type data. ...no consensus was reached as to the desirable research strategy, though it is safe to say that engineering production function studies would receive wide support and encouragement." (Ibid., p.5. My emphasis).

Hence, in addition to the theoretical- and policy concerns, what is at stake in this controversy is also a methodological issue: whether or nor it is possible to construct a pure technological relation from 'engineering data' (or 'raw technological information') and - if the method of statistical aggregation from 'micro' to 'macro' will do the job in the absence of this kind of 'raw technological information'. We can now also begin to grasp the peculiarities that make up the division of labor among engineers and economists: the former is engaged in the work of mixing up purely technological relationships with economic magnitudes, the latter is busy occupied with the difficult task of cleaning up after the former so that the problem of technical maximization can be solved - if not at the level of the firm, then perhaps at the aggregate macroeconomic level. In a later publication, Brown (1968), still grabble with the problem of purification: "It is extremely difficult to construct production functions without including some economic magnitudes...However, it $i s$ possible to construct a purely technological relationship..." (Ibid.,p.10. Brown's own emphasis).

In addition to Salter (1960/1966), Brown (1967), Solow (1967), Brown (1968) recognition of the difficult task of constructing a purely technological relation, one could add more recent as well as earlier work emphasizing the significance of the pure qualities of the Other production function: Shephard (1953/1970), a good friend of the well known game theorist Oskar Morgenstern is quite clear in these matters. In the reprinted version of his original monograph, the author states: "In economic theory the production function is a mathematical statement relating quantitatively the purely technological relationship between the output of a process and the inputs of the factors of production...for any set of inputs of these factors, the production function is interpreted to define the maximal output...the production function is ideally a statement of purely technological alternatives, without regard to their execution...The production function is regarded here as a mathematical construction for some well defined production technology. This technology consists 
of a family of conceivable and feasible engineering arrangements, not restricted necessarily to particular realizations found in practice...If the production function is to define purely technological possibilities, the available means of a firm or other production unit are not relevant.” (Ibid, p. 3, 4, 5). Following Heathfield and Wibe (1987), the production function " is furthermore a purely technical relation which can be constructed without any reference to market conditions or prices. It represents the choice set. Economic aspects enter only when it comes to choosing one of these possible input-output configurations." (Ibid., p.12-13).

To summarize, the work towards a neoclassical production function involves a division of labor among engineers and economists in which the latter seek to purify the 'engineering production function' from less relevant technical properties and engineering arrangements - what is termed here 'technical purification', as well as from entities that is associated with the selection of technical alternatives based on factors markets and their associated prices and costs - what is here termed 'economic purification'. When this work of double purification, both technical and economic, has been completed to a success, the neoclassical economists have obtained a production function that is a 'purely technological relationship'. But then again, it should be emphasized that such a purely technological relationship, hence this Other production function, is not an end in it self, rather it is a necessary beginning and premises in the neoclassical theory of the firm and production as well as for paving the way for a neoclassical analysis into such a central topic as the problem of economic optimization under conditions of scarce resources. Only a neoclassical production function is worthy such a task. Neither the engineering production function, nor the Other production function will suffice.

\subsection{Constructing the natural price - transforming the Other production function, solving the} problem of economic optimization

As already indicated, the Other production function does not by it self solve such a central neoclassical economic problem as economic optimization in a world of factor prices and costs simply because it is purified from such economic magnitudes. But are economists not interested in factor prices and costs and their associated markets? Of course they are, but not until later, that is, after completing the transformation from an 'engineering production function' to the necessary Other production function consisting of a 'purely technological relationship'. Having once obtained 
this pure technological production function, the neoclassical economists embark on yet another task, that of transforming the Other production function into one that is also relevant to the neoclassical analysis of the problem of economic optimization.

The division of labor between engineers and neoclassical economists has already been touched upon. The making of this division also prepare us for what has yet to come - an emerging, and rather interesting distinction between technical maximization and economic maximization, or optimization:

The problem of economic optimization carries two different connotations, i.e. as a problem of maximization and as a problem of minimization. When the economic world exists without (factor) prices, i.e. there are no revenue and cost to optimize production quantities against; the problem of economic optimization is identified as one of maximization only. A world without a price is a world without scarce resources, which is a world without budget constraints and costs, and in this world, the solution to the problem of economic optimization becomes identical to solving the problem of technical maximization, represented by the Other production function consisting of the 'pure technological relation'. In a world without a price, the Other function will thus stand in for a neoclassical production function and represent the solution to the problem of economic optimization. But this world without a price is of little interest to economists. Following Shephard (1953/1970) “ ...the situations of interest in economics are those for which not all factors of production are free." (p.4).

The reader, now sensing the emergence of a paradox, is justified in doing so. The emerging paradox can be stated in the following way: since neoclassical economists, like most other economists, are interested in a world with a price - why then, go all the way through so much difficulties and hard work of economic purification so as to produce the Other production function? Why not settle with, let say the convenient two factor analogy associated with technical purification? I will return to this emerging paradox in a moment.

When the economic world exists with factor prices, the problem of economic optimization is also one of minimization. In this more complex world the existence of prices signify an end to unlimited resources. The existence of prices thus signifies an end to an economy in which factors of 
production could be obtained for free. Unlimited supply is now replaced with a condition of scarce resources - reflected in the very existence of factor prices and their associated markets and costs. In this world, the problem of economic optimization cannot be solved alone by the Other production function - yet it is still a necessary beginning towards an optimizing solution. So this is the moment in which the Other production function has to pass through the crucial transformation so as to become a true neoclassical production function - that is, one capable of dealing with the central problem of economic optimization in a world of prices and scarce resources:

How then, can a problem of technical maximization be transformed into to a problem of economic optimization in a world of scarce resources and associated factor prices and costs? Or put more precisely, how can a purely technological relation be obtained, then transformed into one which embed economic magnitudes such as factor prices - while simultaneously maintaining both its technological purity as a solution to the problem of technical maximization as well as representing a solution to the problem of economic optimization? Recall, that such an embedded-ness of economic magnitudes - or impurity of technological relations, was a fundamental problem associated with the 'engineering production function'.

After the multiple transformations and purifications in the hands of neoclassical economists, what was originally a problem of impurity, i.e. the presence of relative factor prices in the 'engineering production function', has now become part of the solution: By imputing factor prices into the already purified Other production function, a true neoclassical production function has finally been obtained. Now at last, the problem of economic optimization under scarce conditions can be solved - at the point of equilibrium produced quantity in which marginal cost equals marginal revenue, that is, at the point in which the cost of producing one more entity of a good equals the revenue of one more good sold.

The price thus imputed by the economist, it must be emphasized, is to be "distinguished from “actual” or "market" prices [...it is] called "natural”...” (Kurz and Salvadori, 1995 pp. 1,2. My emphasis). But can there be added any further qualifications of the 'natural' price thus imputed? This is an important question insofar as it goes beyond a negative definition in which the natural price is defined as being different from actual or market prices (and associated impurities). It is also an important question insofar as it goes beyond attempts to give an operational or quantitative 
definition, e.g. that 'natural' prices can be equated with a statistical average of actual market prices. So, what (more) makes the price 'natural'? Going along with Kurz and Mannes' distinction above, it is further suggested here that actual or market prices are defined through the existence of a particular relation between the price and the good sold on the market by a producer. The actual or market price is thus a price that identifies a particular producer of a good - in this case the price, the producer, and the good are not separated entities, but related and defined through each other. The natural price is different, because it does not denote this kind of particular identity relation, but general one. Hence, contrary to actual or market prices, the natural price imputed by the economist holds this general and distributed quality of being no ones in particular-as a price to be taken as given for all, while keeping them in place. Only when all concerned have been made into such natural price-takers can it be imputed and made useful in calculating a solution to the problem of economic optimization. The natural price is thus separated and purified from any particular market relations and identities. This general quality is also what distinguishes the natural price form the less pure relative factor prices associated with the 'engineering production function'. Only the natural price is worthy to be imputed into the already purified Other production function so as to pave the way to a satisfactory solution to the problem of economic optimization.

After this last crucial natural-price-imputing transformation, the Other production function has become identical to a cost-function, finally allowing the neoclassical economist to solve the problem of economic optimization in terms of cost-minimization, while maintaining the solution of the technical maximization problem. Hence the neoclassical 'duality' (after Sheppard, 1953) between the Other production function and the cost-minimizing, true neoclassical production function: The two functions can now be translated into each other, yet both describe and represent equally truthfully the same perfectly purified technological relations.

As pointed out by Chung (1994) and other neoclassical economists, reaching equilibrium implies that "profit is zero at any price and therefore that the conventional profit-maximization procedure is broken down" (Ibid.,p.96). Accordingly, at this "natural" point, "profit-maximization" transforms into - or become identical to, solving the problem of economic optimization in terms of "cost minimization". And following the important neoclassical theorem of Euler - reaching equilibrium, each factor of production is paid their marginal product, and hence, the total product is exhausted. Thus, there will be no more profit to the entrepreneur, all still according to Euler's theorem, which 
has "played the central role in the marginal product theory of income distribution" (Chung 1994, p. 96. My emphasis).

For a more detailed historical exposition into the controversy associated with Euler's theorem and it's followers such as J.B. Clark, see also Joan Robinson (1934/1951). Drawing up the implication from Euler's theorem, she states, much in the same way as Chung did 60 years later"...when competition is perfect the wage for each factor is equal to the value of its marginal physical product and there is no residue for the employer [or entrepreneur]... it is only if competition is perfect that the earnings of the factors are equal to their marginal physical products, and only when profits are zero that the earnings of the factors absorb the whole product." (p.10-11. My emphasis).

Following Robison (1934) and Chung (1994) the absence of residuals suggests that the factors of production has exhausted the total product, and hence that the problem of economic optimization under scarce conditions has been solved. Conversely, the presence of residuals suggests that the problem of economic optimization has not been solved. To take a relevant example, Abramovitz's (1956) residual as a 'measurement of our ignorance' and Solow's (1957) naming of the residual as 'technical change': “It will be seen that I am using the phrase "technical change" as a short hand expression for any kind of shift in the production function. Thus slowdowns, speedups, improvements in the education of the labor force, and all sorts of things will appear as "technical change". (Ibid., p. 312. Last emphasis mine) ${ }^{4}$. As the writings unfold, the residual that first was associated with 'all sorts of things' slowly transforms. While it was still 'all sorts of things' it remained within the frame of a strict statistical interpretation in which a residual is what is left unexplained in the analysis after the two variables denoted ' $\mathrm{K}$ ' (capital) and ' $\mathrm{L}$ ' (Labor) have been accounted for. Then the residual slowly transforms into the less strict 'technical change' including also the specific connotation "the observed rate of technical progress... [that also] must be embodied in new plant and equipment to be realized at all” (Ibid., p.316 My emphasis). As the residual becomes loaded with these more specific statements, it poses new problems. For example, it becomes increasingly difficult to maintain the distinction between capital (and associated investments in capital goods on factors markets) and technical change as "this raises problems of definition and measurement even more formidable than the ones already blithely ignored" (Ibid., p.317). Yet, the distinction between capital and technical change is reinforced at the very end of the paper so as to make the latter exogenous to both firms and associated factor markets: "Gross output per man hour doubled over the interval, with $871 / 2$ per cent of the increase attributable to technical 
change and the remaining 121/2 per cent to increased use of capital.” (Ibid.,p.320). In Solow's (1957) work it is assumed, in accordance with Euler's theorem " That factors are paid their marginal product [...] an assumption often made" (ibid.312) - and explicated further by the author, as " assuming the hypotheses of Euler's theorem" (ibid., p.313), "my assumption of competitive factor markets" (ibid., p.317), " the assumption that factors are paid their marginal products" (Ibid., p.320).

Drawing upon Euler's theorem, one could qualify Solow's interpretation of the residual by emphasizing that, once calculated and thus brought into existence by the neoclassical economist, the residual also indicates that the total product was not exhausted and hence, that factors of production are not paid their marginal products. Adding such an interpretation of the residual to Solow's list of interpretations would then militate against the existence of any equilibrium condition, following Euler's theorem, in which the total product is exhausted and the factors of production are paid their marginal product. However, going along with the Other production function - expressing a pure technological relation, the residual can now be interpreted in its purifying terms as 'technical change'- while maintaining the central theorem of Euler, and followers such as J.B. Clark, Solow, Samuelsson and others. Tobin (1967), also present at the conference among eminent economists, comments upon the presence of equilibrium conditions in Solow's (1967) work. Tobin urged “us, among other things, to question the complacency Solow expresses regarding the basic general neoclassical production function. It is a static function... We dodge the difficult problem of specifying the timing of inputs and related outputs by specifying stationary conditions..." (Ibid.,p.53).

The presence of the residual could open up for yet another controversy, let say, a continuation of an old controversy surrounding Euler's theorem and associated work, a theorem so central to the neoclassical theory and calculus of marginal product, -cost, - revenue and income distribution as well as for defining perfect competition, equilibrium conditions and optimum output quantity. Naming the residual as a 'measurement of our ignorance' then re-naming the residual 'technical change' - in perfect continuation with the purified Other production function, solve more than the technical maximization problem for the neoclassical economists. Among other things, also the problem of economic optimization under scarce conditions can be solved - the presence of residuals 
are not any longer an emerging problem in this respect, but becomes part of the solution, as 'technical change', reaching a new given level of 'technical knowledge'.

The Other production function thus seems to serve many problem-solving functions in the neoclassical analysis into the problem of economic optimization:

- The presence of factors prices associated with the less pure engineering production function, posed a problem for a neoclassical solution to the problem of economic optimization. By imputing factor prices into the already purified Other production function, the problem of factor prices becomes part of the solution. I will call this work of transformation into a true neoclassical production function, for price-purification in order to emphasize the passage from a less pure world of relative 'engineering prices' (the 'engineering production function'), to a pure technological world without a price (the Other purified production function) then transforming the latter into a neoclassical world that only include such 'natural' factor prices that are imputed by the neoclassical economist (the neoclassical production function).

- Having once obtained a neoclassical production function, the presence of residuals posed an emerging problem for a neoclassical solution to the problem of economic optimization, first expressed as a 'measure of our ignorance'. By interpreting the residual in perfect continuation with the purified Other production function as 'technical change' - then reaching a new given level of 'technical knowledge', the emerging problem of the residual becomes part of the solution. I will call this work of transforming a neoclassical production function into 'technical knowledge', knowledge-purification, in order to emphasize the passage from 'ignorance' to 'technical change', then to a new given 'technical knowledge' a passage that went through the Other production function.

To summarize, there are at least four closely intertwined processes of purification associated with the Other production function: Technical-and economic purification enters so as to obtain a solution to the problem of technical maximization. Having now arrived at the Other purified production function, the neoclassical economist then adds price-and knowledge purification to it so as to finally arrive at a truly neoclassical production function - a 'natural'-'technical law', capable 
of solving simultaneously both the problem of technical maximization as well as the problem of economic optimization under scarce conditions - at any given level of technical knowledge and price.

Without this Other production function, there would be no more clearly defined production technology and technical knowledge, and no more clear solution to the problem of technical maximization, and no more clear solution to the question of what constitutes technical efficiency and technical efficient input and output quantity. By implication, there would be no more clear solution to the problem of economic optimization of output quantities, neither in a world with a price nor in a world without a price. In the vivid phrasing of Brown (1968): "It is not difficult to uncover reasons why the phenomenon of technological progress has become one of the focal areas of inquiry in economics...For the ruling technology sets the conditions for the optimum use of resources; and similarly, a change in technology alters the optimum use of resources." (p.2 Emphasis added $)^{5}$. Hence, without this purified Other production function, that is capable of ruling and setting the conditions for a solution to the problem economic optimization - being an economist would perhaps not be entirely the same any more. Homo economicus it self would not be entirely the same any more - a hybrid entity might perhaps emerge, e.g. one constantly mixing less pure 'engineering production functions' with 'purely technological relations', all the way from micro to macro while struggling to keep the two apart - as if being an eminent economist.

However, there are very few empirical studies into production functions that have actually investigated the possible significance of the physical and material properties of production technologies in the production of more or less hybrid, or conversely more or less purified, entities and identities such as production functions and homo economicus. (The present section is only the first step in such an inquiry). This state of affairs may seem somewhat surprising given the lack of knowledge - already recognized by Abramovitz (1956) and recalled by Brown (1967), Solow (1967) and Brown (1968) into related matters. To be more specific, such an empirical inquiry should pay some more attention to a problem raised by Salter (1960/1966) and expanded upon by Brown (1967) Solow (1967) and Brown (1968), that is, how "extremely difficult [it is] to construct production functions without including some economic magnitudes" (Brown 1968, p. 10). And following Brown once more, I do not say that it is impossible to construct such pure technological production functions, rather I regard such a possibility as an entirely open empirical question. Such 
an outcome may be possible - as it is equally possible that "homo economicus really does exist" (Callon, 1998a, p.51. Callon's own emphasis).

Now the question arises a new: what constitutes an emergent homo economicus? As Callon (1998a) has already pointed out, economists and other humans calculate, but not simply by themselves. Humans equipped with calculative technologies tend to do it in a different way than those without. Such material calculative practices have practical effects so as to produce an emergent homo economicus. In addition to Callon's important point, I would now like to suggest another: a homo economicus worth the name does not only calculate, but it also calculates in a highly specific way so as to solve the twin problems of technical maximization and economic optimization. And it is towards this process of multiple purifications in which those two specific solutions are obtained that we should direct our attention: how is it possible to obtain those twin solutions, both technical maximization and economic optimization-while simultaneously achieving and maintaining pure technological relations? Obtaining those twin solutions, despite all the difficulties recognized by Solow (1957), Brown (1968) and many other eminent economists, is the work of a genuine homo economicus. Grasping the nature and very existence of this emerging creature, carrying the name of homo economicus, seems to pass through this puzzling, perhaps paradoxical, question. It is this achievement - emerging from the hard work of multiple purifications that constitutes a homo economicus worth its name.

Hence, an empirical inquiry into the possible production and emergence of homo economicus can benefit from such an entry point - into the demanding task of purifying production functions so as to obtain this Other production function - in which no relations to markets, associated institutions, and factor prices exists, in which a given state of technical knowledge is made into being - in which the ruling technical law it self is made into being.

\section{THE PURIFICATION OF PRODUCTION FUNCTIONS: MAKING A GIVEN STATE OF TECHNICAL KNOWLEDGE - REMAKING HOMO ECONOMICUS}

\subsection{A note on the methodology of symmetry}


The methodology of symmetry used in this investigation is in dept to the principle of symmetry first proposed by Callon (1986) and Latour (1987) in their investigations of scientific practice. The methodology of symmetry thus adopted means that if neoclassical economists are capable of constructing multiple purifications so as to solve both the problem of technical maximization as well as the problem of economic optimization, then we must grant to the actors and practicians out in the field the same capacities as we grant to neoclassical economists. If we do not, then this will amount to assume a priori that homo economicus could never exist, nor be brought into existence. Since I have already described and argued in some detail that neoclassical economists are perfectly capable of such purifications so as to create an emergent 'homo economicus', the application of the methodological principle of symmetry imply that such purifying capacities must now be extended so as encompass the rest of the economy of economic agents and practices. If this also means that "aggregation is inevitable", then - following Solow (1967) once more, I will just say "relax and enjoy it"! Or with Latour(1987) "Follow the actors"!, with the slight symmetrical qualification that we now have to follow the (f)actors through all their possible purifications.

The case presented below is rather long, but should be to the point in addressing the way economists and engineers, in close association with computer based calculations and computer based manufacturing machines, embark on the demanding collective task of organizing the purification of production functions for national economies as well as for firms on both sides of factor markets ${ }^{6}$.

\subsection{Constructing the supplier side of the market-purifying the technical relations.} Approximately at the time of publication of Samuelson's(1980) eleventh edition of "Economics" in which the 'Technical Law'(p.501) of production functions appeared, economists applied its computer-powered cousin while aggregating all the way from micro-to-macro. As such it also represented a possible new computer-based solution to the kind of aggregation and method problems commented upon by Brown (1967) and Solow (1967) and many other eminent economists. Could this computer-based tool finally establish the link between micro and macro - in effect produce a technological solution to what was hitherto a major theoretical and methodological problem within economics? Indeed, as will be described and argued in more detail below, the problem of aggregation from micro-to-macro could be solved, and in effect transform a major theoretical and methodological problem in economics - with due help of a computer based 
calculation technology. The first version of the computer-based simulation tool was developed within an industrial research institution funded by the largest industry association in the country. In addition to economic funding from the industry association (members of the industry association paid a yearly membership fee calculated as a percentage of their labor cost), representatives from IBM were also encouraging the development of the first computer-based version. The 'micro-tomacro' model that emerged was able to carry out a simulation that calculated the economic impact of technical change for a nation. The equations making up the computer powered production function included more variables than was usual in the standard textbook version. For example, there were separate production function estimates for firms belonging to different sectors and industries in the national economy. Further more, by allowing for aggregation across sectors and industries, the end result would summarize so as to fit $^{7}$ into the national accounts. In the model, technical change is assumed to be a shift towards a better state of technology, being homogeneous and exogenous to the firm, and embodied in new capital goods. At any given time, the technology's technical performance characteristics sets an upper 'technological constraint' that defines the maximum possible output for all firms in a given industry. Hence, the solution to the technical maximization problem is assumed to be exogenous to the firm. This solution is stated as a mathematical function without any embedding of relative factor prices - in a way similar to the purified Other production function associated with neoclassical economics. The economy and associated entities such as markets and firms enters 'after the fact' so to speak, when the firm is investing in the capital goods embodying the already purified technology (the amount invested being endogenous to the firm). Labor is the only factor that enters the production function directly, while assuming it to be homogeneous across all firms and industries. Capital stock enters the production function indirectly via the abovementioned investments in new capital goods, via the associated depreciation and via the measured effects on labor productivity. If the firm invest in new (in the model, as in neoclassical theory 'new' always means better or improved) technology in a magnitude that more than compensate for the tear and wear of the existing production equipment, then this is represented in the model as a outward shift in the production function towards a (new) solution to both the technical maximization problem as well as that of economic optimization ${ }^{8}$. The economist performing the computer-based simulation was equipped with the option of changing parameters in the model. The effects induced by the analyst entering an 'exogenous change' in the form of improved production technology could then be read off directly from the computer screen at the firm level ('micro') as well as at the aggregate level represented by the national accounts 
('macro') in such terms as employment levels, productivity and economic growth. One such simulation was conducted in an effort to formulate national technology policy as part of a Swedish governmental investigation: the Computer- and Electronic Committee (CEC). Among the other members of CEC were professors from the engineering sciences, notably within the discipline of manufacturing systems.

In 1984, after six years of work, the committee presented their final policy recommendations: "Technical progress at the macro-level are usually measured with the help of so called production functions. Such estimates almost always result in a "residual" which cannot be explained by increases in capital and labor. This residual, called the 'technical factor' has been large and increasing in most countries after the second world war....A one-sided and earlier introduction of the new technology by foreign competitors will give an immediate impact on the economy of Swedish companies and significant larger and long term employment effects. In the simulation case, real wages adapted after a few years to the new competitive conditions and the effects on employment became zero. This is the kind of results one can expect from traditional theoretical economics way of reasoning (CEC in SOU:1984, p.78,80).

Going along with Solow's (1957) purifying interpretation of the residual as a 'technical factor' radically narrows the problem space to one identical to solving the problem of technical maximization: if Swedish companies do not measure up with their foreign competitors in terms of an equally fast introduction of the advanced computer-based manufacturing technologies, then this will have less desirable effects on their competitiveness and the nation's level of employment. These results were not only supported by 'traditional' economics theory in the textbook form, but also greatly enhanced through the computer-based micro-to-macro simulation of the economy - in which the purified technological relations were translated into computer algorithms so as to produce the simulated results. The computer-based simulation was thus inscribed with the neoclassical tradition of the multiple purifications that together define what is the basic (or 'ruling') problem and its solution.

'New' technology becomes part of the solution to the basic problem of technical maximization and hence sets the conditions defining any further progress towards economic optimization. CEC accordingly advised the government to strategically scale up the technology policy supporting the 
introduction of computer-based manufacturing systems. "Increased support should according to CECs judgment be feasible in the form of more systems for demonstration within the area of computer-based manufacturing techniques.” (Ibid., s.122). 'CECs judgment' - a singular voice, a singular calculation, a singular solution: more computer-based manufacturing systems. CEC had pursued a similar recommendation with success a few years earlier. The line of argumentation did not differ from 'traditional' economics: “ ...it should perhaps be explicated, although it is probably self-evident, that by new production techniques it is meant here only those news that are increasing productivity." (CEC in SOU:1981, p.22. Emphasis added).

CECs simulations and calculations share with neoclassical theory this assumption of a perfect identity between 'new' technology and increased productivity - what is also termed the 'selfevident' in CECs (1981) report. There also seems to be a close similarity between CEC and neoclassical theory regarding the relative existence of the 'new' technology. Following Shephard, the technology does not actually have to exist or to be "found in practice" (Ibid., 1953/1970, p.4). The members of CEC to be sure, recognized the existence of the technology, notably its knowledge demands. Yet CECs members also argued for its development and subsequent diffusion to industry - as if the existence of the new technology was still somewhat uncertain: "A characteristic feature of computer-based production techniques is that it put increasing demands on knowledge accumulation and knowledge-cooperation. Further more, it demands, if the diffusion of the technique to the industry shall not be slowed down, increased support so as to diffuse experiences...Against this background as well as the manufacturing industry's large significance to the Swedish economy, increased support to collective research- and development becomes of central significance both for the development and the diffusion of the technique” (Ibid., p.58)

One of the engineering-professors in CEC was already a scientific advisor to the 'collective' engineering research institute now being of strategic importance. This professor was soon also to become head of CECs proposed program for the development and diffusion of FMS and engineering science knowledge to the industry. Governmental funds were allocated to the FMSprogram. The budget of this FMS program comprised 40 million SEK over the years 1983-1987. The total amount of money that the Swedish state allocated to FMS-related research, development and diffusion over the years 1982-1989 adds up to 225 million SEK (OECD, 1989). In addition to the two already existing sites, new 'collective' research sites dedicated to computer-based 
manufacturing were established in three other cities across the country. The number of employees increased from 75 in 1980/81 to 170 in 1989. Turnover increased from 12 million SEK (in 1977) to 70 million SEK (in 1989).

'CECs judgment' traveled far - all through the government and the parliament. Yet, the homogeneous voice had to be produced. Members of CEC that identified them selves as representatives from the national labor union were titled 'secretary'. Other members that identified themselves as representatives from specific political parties in the parliament were titled 'parliament representatives' without any further differentiation. The only ones that were actually differentiated with some more precision were those titled 'doctor in economics' 'engineer', 'professor'. In this way, scientific objectivity was produced while allowing for a differentiation and subsequent division of labor according to the relevant scientific competence involved.

Ceteris paribus, a professor is more competent than a doctor, which is more competent than a 'secretary' etc. The union leader labeled 'secretary' described what she saw as the now dominating perspective of CEC as "technical blindness" in a written formal reservation against the proposed technology policy. The reservation was put in an appendix in the CEC report. When arguing for other relevant technologies than those associated with manufacturing and engineering, or when arguing for other relevant perspectives on the problem to address, such as work environment and industrial democracy, she described her experience as "they [the other members of CEC] listened politely. Then they went on as before". However, there might be other 'appendices' in this CEC committee, albeit more central than the one that was actually relegated to the appendix. The other humans (both economists and engineering-scientists) that 'went on as before' while going along with the simulated results from the computer-powered micro-to-macro model, seems to constitute yet another appendix, to the calculating technology it self. As it turned out, the computer-based micro-to-macro model acquired a central role in framing the problem and the solution, to draw the finer distinctions and boundaries between what was part of the solution, and what was outside that particular frame. Hence, the computer-based simulation model, now capable of performing the complex calculations and aggregations that no fragile individual human can perform, simultaneously also produced both framing and overflow (Callon, 1998b). Framing and hence inclusion was produced as the computer-based tool outperformed calculative capacities of the remaining humans - they were going along with it, in effect delegating calculative capacities and 
competences to the tool while becoming central appendices to be included in the now emerging 'center of calculation' (Latour, 1987). Overflow is what this 'main-frame' of calculation cannot contain without facing a break down - in this case, represented by deviating female voices speaking of 'technical blindness', and thus to be excluded from the emerging center of calculation.

The professor in manufacturing technologies, member of CEC and later also the head of the governmental funded FMS-program explained further that concerns such a work environment and industrial democracy were responsibilities to be distributed to the individual company. Another engineer that was responsible for technical development within the FMS-program added: "A program that is geared towards technical development needs humans that are occupied with the technique - not negotiating-people". FMS was to be protected from such negotiating people and their concerns.

The case has so far accounted for the successful division of labor among representatives of engineering-science and 'traditional' economics in constructing a purified macro-economic production function. It is successful, not only because the results of all this work confirmed 'traditional' economics theory, but also because this very success simultaneously confirmed the success of the center of calculation it self: what economics had struggled with for so long, to solve the theoretical and methodological problems associated with aggregation from micro-to-macro, seemed now to be solved by a piece of technology, the computer based calculation tool. The 'microto-macro' success can also be measured in quite precise monetary terms in the allocation of the 225 million SEK related to the development and diffusion of FMS. Creating such a success involved hard work. The success went through 6 years of committee work in which the number of published reports and pages exceed most of what Swedish governmental investigations had produced so far. Inscribed into those texts were also the imprints left from the now successfully calculating tool confirming its own success while confirming that of 'traditional' economics.

Now the question arise, how did this successful division of labor among economics and engineering science pass through the next crucial selection mechanism as it moved from the approval in the parliament and the government, towards the factors market for machinery? Being so far a successful 'possible' macro-economic production function, as represented by computer-based calculations, 
texts and money (the governmental budget allocation), it was now also to become one to be 'found in practice', that is, one made of steel.

Also this successful transformation from being texts, calculations and money towards one made of steel required hard work. It turned out that the engineering scientists also were sophisticated neoclassical economists in solving such a demanding task. This is what happened: the engineering scientists divided their time and labor by attending to several related sub-tasks: The professor in manufacturing systems operated part time as a CEC member arguing for the existence of a demanding technology requiring scientific knowledge, and part time bringing that technology into existence. Together with two fellow engineers, he proposed a design of a computer numerically controlled, CNC-machine that never had existed before - one with a 45 degrees tilted machine table. The second engineer that participated in the design was the one that previously had helped the ministry of industry to focus the CEC investigation on the interface between CNC-machines and industrial robots. He also holds the position as director of the 'collective' engineering institute that were now expanding with due help from CECs strategic recommendations. The third engineer that participated in the design was also a technical project leader in the newly established state funded FMS program. The professor in manufacturing systems and member of CEC, was heading the very same FMS program.

The soon resulting tilted machine table design would in principle allow for a more efficient automation of the loading an unloading of parts in the machine. An industrial robot was included into the design so as to carry out the work of loading and unloading the machine with the tilted table. The design was proposed at a design meeting at the site of a Swedish machine tool manufacturer. The three engineers were members of a product development board at the machine tool company. One of them presented the prototype of the tilted machine bed design in the form of plastic bricks. The next version of the prototype was made of plywood as a full-scale machine tool and exhibited at an industry fair in Sweden. The third version of the prototype was also in full scale, but this time one made of steel and exhibited at an industry fair in Germany.

The engineer professor and director of the expanding 'collective' research institute, explains the tilted machine bed design: " to machine unmanned or limited so and make sure that the humans work daytime and capital around the clock". Before becoming a professor and director, he had for 
several decades participated in developing industrial robots and applications in the world's largest company of this sort. As Tobin (1967) has already pointed out, neoclassical economists never associated time to the task of solving the technical maximization problem, which make this engineer no less sophisticated than neoclassical economists. We have to engage the classical contribution from John Stuart Mill (1848/1965) to fully appreciate such considerations. Allowing machines to work around the clock " is evidently the only economical mode of employing them" (p.131). But in contrast to Mill, this engineering scientist does not mix up the two problems, that of technical maximization and economic optimization. There are no such less purifying associations to relative factor prices, which can be inferred from Mill's talk about what is the 'only economical mode'. In addition, the engineering scientist not only makes an association to time, but also considers the very distribution of productive time between the two neoclassical factors of production. All these associations to time are made without embedding the less purifying relative factor prices into the solution. So this actor seems to argue that: Ceteris paribus -that is, without any embedding of relative factor prices, it will always be more efficient if capital can be utilized around the clock. Conversely, capital that is not utilized around the clock is another word for less productive capital, which is yet another word for an emerging unsolved technical maximization problem. Hence, inscribed into the very design of this machinery emerges a perfected solution to the problem of technical maximization - at last bringing time back in, all around the clock. But inscribed into this design emerges also a societal ('macro') division of labor among humans and non-humans - all around the clock. Such inscriptions and associations to time make engineering scientists no less sophisticated than neoclassical economists

The other engineering scientist, the technical project leader dedicated to machines - not 'negotiating people', introduced the dimension of time in association to possible interruptions when he explained the tilted machine table design: "So the purpose of all this was to manufacture components in small series by bringing down the costs of fixtures and reduce the amount of interruptions. It was a simple as that, besides allowing for the robot to work in loading the machine." In addition to the distribution of productive time among factors, we can now also see that engineering scientists are perfectly capable to associate time to several possible dimensions of the technical maximization problem such as the unproductive time of possible interruptions in the machining. Smaller series can be part in creating these interruptions. But fixtures can be designed to solve such an emerging technical maximization problem. 
The third engineering scientist, the professor and member of CEC, had not only recognized the significance of time, and the productive time of different lengths of production runs, but also recognized that a solution to the problem of technical maximization had to pass through the possible existence of product variations. This actor seems to hold the view that product variants could hardly be accommodated in a manufacturing process designed to manufacture a given homogeneous product. He also recognized the "almost natural law of economies of scale" associated with a homogeneous product. Yet, he opted for another solution - one that also would differ from the now familiar neoclassical assumption of a homogeneous product. Hence, in practice, this engineering scientist added to the homogeneous neoclassical specification of the technical maximization problem, the state of "very flexible variants". This possible and actual state of affairs thus called for the solution represented by flexible manufacturing systems (FMS). As already noted, the professor and member of CEC, also became head of CECs proposed state funded FMS program.

There is no mentioning of relative factor prices included in this specification of the technical problem to solve, yet this engineer formulates a sophisticated theory of the possible existence of heterogeneous products ('very flexible variants') when explaining the significance of the FMS technology. The solution to the problem of technical maximization has now to pass through, not only the distribution of time among factors of production, the productive time of various lengths of production runs, but also heterogeneous products. Even this latter, makes engineering scientists no less sophisticated than neoclassical economists. Indeed, Brown (1968) was perfectly right in assessing that the engineering production function typically operates with a more complex set of technical relations than the one associated with a neoclassical production function.

All these sophisticated solutions to the technical maximization problem were then to be inscribed into the very design of the emerging FMS. An entirely general macro-economic theory, yet different from the 'traditional' neoclassical one inscribed into the computer-based micro-to-macro simulation model, is thus embodied in the now slowly materializing FMS. The peculiar division of labor between economists and engineers is also embodied in the machines: the former develops computer-based simulation models embodying possible macro-production functions, the latter develop computer-based FMS, embodying possible as well as emerging macro-production functions into its design. Both computer-based simulation, as well as computer-based FMS embodies a 
solution to the problem of technical maximization for the national - 'macro' economy. None of them include into their design such less purifying topics as the embedding of relative factor prices into their solution of the technical maximization problem. Engineering scientists are as serious as their neoclassical counterparts in this collective task of purification. Computer-based FMS is to be considered a purely technical solution. No politics of relative factor prices, or of any other kind to be inscribed into its pure design.

\subsection{Constructing the customer side of the market-making the natural price come true.}

The work of purification does not end at the supplier side of the factor market, but must be carried all the way to the prospective (or actual) customer, while simultaneously keeping the former in place. Only then can a perfectly purified solution to the twin problems of technical maximization and economic optimization be secured. Only then can a natural market be brought into existence. At the customer's site two CNC-machine tools with a 45 degree tilted machine bed were introduced from the machine tool company just mentioned above. The two machines were introduced as parts of a system named FMS - that also became part of the FMS program headed by the professor in manufacturing systems. How can this event be explained?

As it happened, the professor heading the FMS program and the professor heading the 'collective' research institute were also members of a technical advisory board for manufacturing at the customer's site. "So we made a system", the professor and head of the FMS program explained. Together with his colleague, they made drawings of the emerging FMS and argued for its relevance at the customer's technical advisory board. The head of production were invited to visit the professor's research lab in which similar systems with automatic robot loading were exhibited and named 'pilot projects'. During these visits, the head of production were also to be engaged in a project aimed at developing investments calculus of these kinds of flexible systems. One of the problems the project sought to tackle was associated with the application of 'traditional' investment calculus when evaluating FMS alternatives. Among other things they argued, economists' traditional calculus tended to underestimate the returns in terms of increased capacity utilization in the existing vintage of machinery accruing from the introduction of FMS. They were thus arguing for a set of technical relations between existing machines and those to be introduced: Rather than treating the two vintages of machinery as entirely separated from each other, they should be 
calculated together in order to estimate the full capacity effect of the investment. The head of production was also invited to participate at the industry fair in Sweden where the prototype of the machine tool in plywood was exhibited. This exhibition took place in December 1984. Here, timing of investments (recall the comment made by Tobin, 1967) becomes a critical issue:

The 'plywood' exhibition actually took place after the prices underlying the investment calculus were first determined. These prices were already set during the year 1984 and prior to the 'plywood' exhibition. How then, can the cost and the capacity of the investment be calculated if there exists no actual machinery of steel, indeed nothing but a few drawings on a piece of paper, a prototype in plywood and a few plastic bricks? More over, how is it possible to draw these heterogeneous material entities - scattered around in time and place, together into one homogenous purified solution to the twin problems of technical maximization and economic optimization?

Drawing these heterogeneous entities together into one time and place is exactly the kind of work a written investment calculus can perform - especially if it is adequately equipped with a natural price. As will be described further below, the sequence and timing of events, can be drawn together, reversed and made stand still, so that it does not really matter - as Sheppard (1957) so clearly has pointed out by, whether the technology really does exist or not prior to the actual investment calculus. Following Kurz and Salvadori (1995) what actually matters for a satisfactory neoclassical solution, is that (factor) prices are different from the less pure 'actual' or 'market' prices, i.e., a price so general that it belongs to no one in particular - so that the one performing the calculation can impute the price as natural and hence - claim a solution to the problem of economic optimization (or cost minimization).

In the written investment proposal, the FMS alternative were confronted with two competing alternatives similar to those already in operation in the factory. The head of production presented the written report to the board and argued for the relevance of the FMS - including the added returns in the form of increased capacity utilization in the existing (old vintage) machinery. The first step in the FMS investment, comprising two CNC-machine tools, was calculated at a cost of 13 million SEK - with all three steps in place, the investment would add up to 39 million SEK (or approx. $10 \%$ of company turn over). But where did the factor prices for the machine tools came from? Did it come from the actual machine tool supplier? No, the price allowing for these 
calculations came from elsewhere - yet became so general as belonging to no one in particular. The task of constructing the natural price was solved in the following way: During 1984, the head of production invited 8 machine tool suppliers to offer machines. At this point in time, the actual Swedish machine tool supplier was still busy assembling the prototype in plywood and was not even participating with an offer. After a screening of the incoming offers, a German supplier was selected. The price offered by the German supplier was also the one to be imputed in the investment calculus that later came to be presented at the board meeting in May 1985. Here, it is important to note that the investment calculus that went to the board was purified from any particular relations to actual suppliers - no such names were listed - only the aggregate investment cost for the FMS was accounted for. At the meeting, the board voted in favor of the FMS.

In the spring of 1985 - a few months after the 'plywood' exhibition and a few months prior to the board decision in May, the Swedish machine tool manufacturer received an invitation from the head of production to offer two CNC-machines as part of an FMS system specification. The head of marketing at the machine tool company explain further that when receiving the invitation, everything in the design was given, except the specification of the machine tool supplier: Automatic loading and unloading of the machines according to an industrial robot concept on rails, an automatic measuring robot for quality measurement of finished parts, a central computer - even the different suppliers was specified. The FMS was specified as highly automatic: "It was the first system with closed loop in Sweden", he explained.

After approval at the company board in May 1985, the FMS proposal went through a second screening at the corporate level in September the same year. This was a standard procedure when handling such major investments. The head of production explained to this author that at this point in time the Swedish machine tool supplier had replaced the German one. Yet, the price that once belonged to one in particular, the German machine tool supplier, was still maintained in the investment proposal that now went to the corporate level. The company board had approved 13 million SEK for the first step in the investment - neither more nor less. Instead of changing prices and investment costs according to the price now offered by the Swedish supplier, the price once offered by the German supplier was made into a general one, i.e. one that belonged to no one in particular. The price was thus to be made into a given one for everybody concerned - the company board, the corporate board, and indeed, the now emerging Swedish supplier. The head of production took what he saw as the necessary and appropriate action for the general price to come true. $\mathrm{He}$ 
initiated a negotiation with the prospective Swedish supplier so that the offered machines came down to the price that equaled the German one. Thus, there were no residue to be accounted for, when the written investment proposal went through the final screening and approval at the corporate level. The price was turned into a general one - no longer belonging to one in particular, in effect becoming the natural price imputed.

As suggested by Guesnerie (1996) and recalled by Callon (1998a) prices can be both an input and an output of economic calculative agencies. Last but not least, the significance of the written investment calculus in making the general price come true, must be emphasized. It is suggested here, that this piece of paper was instrumental in drawing all the heterogeneous things (machinery made of diverse materials, suppliers, prices and associated capital lay-out, capacity- and market forecasts) together and keep them in place. The transformation of actual or market prices (input) into the natural price (output) seems to be greatly enhanced by a written investment calculus. This is the material inscription that was capable of traveling through the company board all the way up the corporate board, without being modified. Instead, those equipped with such inscriptions are capable of modifying others so as to take the price and make the natural price come true. Here, also such notions as 'engineering choice' (March 1978), and 'qualification of goods' (Callon, Méadel, Rabeharisoa 2002) come to mind.

The Swedish machine tool company also incorporated the costs associated with the other equipment suppliers - after due negotiations they became sub-suppliers ordered under the singular system responsibility now distributed to the machine tool supplier. As it were, the resulting organization of one singular supplier as responsible for the total system delivery was also a requirement governing the FMS program. The selection of a Swedish rather than foreign machine tool supplier was also in line with the same program's emphasis on the strategic importance of Swedish machine tool suppliers for the national ('macro') economy. Hence, as part of constructing the now emerging macro-economic production function also the distinction between the 'national economy' and the foreign- or remaining world economy emerges. As the head of production explained " It is like the hand that fits the glove that we selected this [the Swedish] machine tool supplier" (My emphasis). Then he added, “ They did not influence me - it was a purely technical question - it was as simple as that". This is true, a technical solution that is nothing but purely technical, cannot be claimed to represent a solution to the technical maximization problem. If the technology were to be associated 
with more narrowly defined national institutions (as opposed to the world or the global) of diverse kinds, then it would simply no longer represent a purified solution to the technical maximization problem. The engineer and project leader at the FMS program explained further that the selection of the supplier was based on nothing but 'business' considerations. This is equally true, a market selection that fails to select on purely economic considerations, cannot be claimed to represent a solution to the problem of economic optimization. The other engineer participating in the machine tool design - the CEC professor also heading the FMS program, became " a little bit surprised" when it turned out that it was just this Swedish machinery, with a 45 degree tilted machine table among this world of machinery, that finally passed through the selection mechanism of the market. This surprise is understandable (no irony invoked here), any perfectly purified outcome that finally emerges from the inner workings of the hidden hand of the market may come as a surprise to most people - that is only human. But then again, this case is not simply dealing with fragile humans, but with all the work of purification that enters into the construction of the technical law ruling the natural market. When finally achieved, it is the technical law it self that has become the invisible 'hand that fits the glove'. The market has become the glove - a natural extension and a mirror image covering up the inner workings of the technical law.

Confronted with the purified FMS, the other union leader at the factory floor became worried "We were very scared...we looked into the future, may be in ten years from now, that the staff would be reduced to half the size... But we also understood that we can not stop the technical development. Even we understood that. So we tried the best we could to participate so as to ensure the best possible outcome for the humans at the factory floor". As a regular member of the company board, she did not vote against the FMS proposal.

The FMS had by now traveled as a text through the government and the parliament, through governmental investigations, into subsequent FMS-programs, through the board for product development at the site of the machine tool supplier, through the corporate board at the customer's site. Finally it announces its presence - as embodied machinery, first at the supplier's site during 1986 while assembling and testing the FMS, then at the customer's site in January 1987. All the way without being modified so as to become deviant and less pure. The union leader at the factory floor summarizes the emerging essence associated with this entity: "we can not stop technical development". FMS was now harboring the laws of Nature it self. In the end, being a member of the 
union, or the parliament, or the government, or the company board did not make that much of a difference. The FMS, this embodiment of the 'technical law' made humans and their institutions into its docile servants. Brown (1968) is again perfectly right in assessing that technology is a serious matter, indeed being 'the ruling technology'. Sweden was no exception in supporting its newly created master. The 'technical law' of FMS worked its way through the whole of OECD- as the OECD (1989) report so very well summarize.

When the highly automated FMS finally arrived at the factory floor as machinery, it did not work according to its master inscriptions. It was certainly true that part of the general principles inscribed into its design also were relevant to this customer organization: The distribution of time among humans and machines, timing of production and the lengths production runs according to the many different delivery specifications were of relevance as was the many different product variants to be manufactured. Yet, the machinery was unable to produce unmanned for more than a short period of time, before having an unplanned stop. Machine utilization ratios as well as the quality of the machined parts became part of a rapidly increasing problem for this organization as well as for their customers: The tools in the CNC-machines were first to be discarded and replaced with new ones that fitted the machining task. Then humans at the factory discarded the programs and replaced them with new ones that added functionality in the machining while reducing the number of program errors associated with the first program. The material handling robot's gripping fingers were reconfigured so as to fit all the different variants of the work piece. Yet the robot continued to drop the work piece. It turned out that program error also was part of the industrial robot's material handling problem. Yet still another part of the problem was the shelf the robot was picking and placing the work pieces. Also the shelf had to be reconfigured. Hence, the observation that the industrial robot dropped the work piece triggered a rather complex process of problem detection among the humans at the factory floor. When they investigated the issue it turned out that there were no single source of error for this strange behavior of the industrial robot. Both engineers and machinists learned a lot about problem detection and came up with several solutions along the way. The engineers participated in re-designing the tools in cooperation with a tool supplier; the machinists redesigned the shelf themselves.

With these reconfigurations in place, the material handling as well as the quality of the machined work piece was considerably improved. However, the automatic quality measurement robot discarded the improved work piece and demanded numerous stops in the machining for quality 
adjustment. Humans at the factory floor regarded many of those demands as out of order, once they had manually measured the quality of the finished parts themselves. "We had a lot to do" the machinists explained. Such adding of non-humans (e.g. new programs, tools, gripping fingers, shelf and manual measurement equipment) and humans to the system design, compromised the fully automated 'closed loop', but contributed positively to a machine utilization ratio that for more than a year had gravitated around zero. Finally, the engineers discarded the automatic quality measurement robot. That improved machine utilization ratio even further. Then the gearbox in one of the CNC-machines collapsed. Despite many years of serious efforts to make automatic FMS part of the solution, Nature and its associated 'technical law' were starting to fall apart. Certainty was replaced with uncertainty - there were no longer any 'self-evident' solution to the problem of technical maximization, nor were there any 'self-evident' solution to the problem of economic optimization. Being now identified as an emerging problem rather than as the solution, the FMS was finally discarded some eight years after its arrival. The machinery that in due time was scheduled to be replaced by FMS went on as before. Together with machinists and engineers, the "old vintage" machinery made the day.

How can such a reversal and redistribution of what is certain and what is not, what is the problem and what is the solution be explained? According to the engineer and CEC professor participating in designing the system, there is certainly not anything wrong with the FMS. Hence, there is no such reversal and redistribution to be explained, since the FMS still is the solution. The humans, their institutions, and a few components failed, not the FMS: "Yes, one has to distinguish between failures in the principle system and failures at the individual levels of components. Your account [read: this author's account, although a longer version of this one. See Tryggestad 1995, especially pp. 159-303, for the longer one] does not demonstrate failures at the principal level but on the component level, as well as failures concerning the market and the way [the company] administrated the project" (My emphasis). FMS, this general macro-economic theory harboring the 'technical law', can in principle not be a failure. So there must be other failures, associated with more fragile individual elements, such as components, the humans inside the individual company, and outside them, there are the 'market failures'.

This particular way of distributing failures among the many entities make engineering scientists no different from neoclassical economists: "it cannot be what must not be", or so the neoclassical word 
says $^{9}$. According to the now seventeenth edition of 'Economics' (Samuleson \& Nordhaus, 2001), 'technological advance' - not regress, is the rule in a well-functioning market economy: "Is the opposite case - technological regress - possible? For a well-functioning market economy, the answer is no. ... Inferior technologies tends to be discarded in a market economy, while more productive technologies are introduced because they will increase the profits of the innovating firm." (Ibid.,p.115).

The FMS was sold as individual items on the market for second hand machines in the late summer of 1995. Such second hand machines hardly seems to qualify as entities representing 'technological advance' as they are about to be 'discarded' in a well functioning market economy. But what does 'discarded' really mean in standard economics? Does it also mean to be exchanged as capital goods on a market for second hand technology? Not at all:

Following once more the seventeenth edition of 'Economics' (Samuleson and Nordhaus, 2001) 'market failures' may translate 'technological advance' into 'technological regress': "When there are market failures, however, technological regress might occur even in a market economy" (Ibid., p.115). 'Market failures' - not technology, is to blame for the existence of 'technological regress'. Engineering scientists and eminent economists speak with one voice when failures and associated impurities are distributed between the two entities. This particular way of distributing failures is far from symmetrical as it distributes all sources of impurities to the market and no sources of impurities to technology: Impure technologies (or 'technological regress') are a consequence of impure markets (or 'market failures) - not a cause or a source of impurities. Pure technological relations and their protection - not the protection of perfectly functioning markets, seem to master economics when failures and associated sources of impurities are to be distributed among the two entities.

There seems to be a few additional implications emerging from this kind of asymmetrical distribution - apart from the very reproduction of a pure and protected technology separated from the market: 1) There should not exist a second hand market at all for technologies in a well functioning market economy since such technologies hardly can be identified as representing the 'advanced' technology, i.e. the one to be purchased and introduced. 2) Even the most perfectly competitive of second hand markets for technology must now be judged accordingly, as basically a 
'market failure' - since second hand technologies can hardly become anything but the impure as in the already 'discarded', 'the inferior', 'the regress'. But is there no price to pay, or no costs to incur, for producing and protecting pure technological relations? Are there no costs associated with maintaining the neoclassical distinction between purified technology and markets? In the last section below, I will return to this question.

\section{THEORETICAL AND PRACTICAL IMPLICATIONS}

What Adam Smith claimed for the labor market - the propensity to organize and master it, I would now like to extend to the Other factor-market. These markets can become natural in degrees. When they become very natural, as if harboring a 'ruling technology' and a 'technical law' consisting of pure technological relations, they are also very highly organized towards a homogenization of what is the problem and its solution. In this final section, the significance of material inscriptions and associations in producing this kind of homogenization will be summarized in an attempt to extend Smith's theory of the masters and servants making up the political market:

The success of FMS was not given in the order of things. Instead, 'success full' order had literally to be inscribed into the technology, e.g. as in the CEC report on the 'self-evident' productive capacities of the 'new' technology and when calculating the economic impact from the new technology in the micro-to-macro simulation. The success had to be produced. Nothing was allowed to interfere into its pure principles, such as 'negotiating people' and the like. In the case of FMS, we heard about deviant voices, fearful voices, the impure voices - notably the few female voices, that become part of the 'negotiating people' to be excluded. The work of purification continued so as to exclude alternative technologies and machine configurations, thus narrowing down the relevant problem space to that of integrating CNC-machine tools and industrial robots into FMS. Here the work of purification continued with the help of additional inscriptions in the form of a written investment calculus, constructing and imputing the natural price while favoring the FMS alternative. So, homogenization is an outcome and achievement of the hard work of purification in which heterogeneous materials, tools and inscriptions are mobilized. Once successfully brought into existence, the purified FMS harbored the forces of Nature and the 'technical law' that no one can resist any longer. The pure FMS is thus constructed from existing institutions of society, such as the nation state, the labor union, the parliament, the government and associated investigations, the corporate board, and the factor markets, and not to forget the twin institutions of science, the 
economic- and engineering sciences respectively. All the work of making machinery and associated factor markets part of a non-political nature has now turned into a success. FMS turned into a master - ruling and setting the conditions, demanding private and public money and scientific knowledge, turning humans and their institutions into its docile servants. In effect, the particular organization achieved through all this work of purification is akin to a linear innovation-diffusion model in which science and technology is made into the independent source of progress to be transferred to what comes after, that is, the rest of society, including the economy and associated markets and firms ${ }^{10}$.

Yet, this is also the particular moment that neoclassical economists take as their starting point and premises when formulating what they consider as their universal 'technical law' and 'hard-core', i.e. an entity in which no associations to institutional arrangements exist. By so doing, neoclassical economists generalize, not only a particular case of perfect purification so as to make it into their own universal 'technical law', but at the same time they take a temporary outcome from a successful process of purification to represent technical knowledge as such. In this way, technical knowledge becomes a given entity - as in the 'self-evident', deprived of the relations and the history that made it into being.

Neoclassical economists have justified their very strong focus on the particular moment in which successful purification is achieved on the grounds that it is convenient. It is certainly convenient, but the associated costs remain outside the convenient frames of their 'hard core ${ }^{11}$. So, going along with Callon (1998a, 1998b) I would like to suggest that convenient frames participate in producing the 'markets failures' economists - and as we have now seen, engineering scientists (!) merely claim to observe. To be more specific, economists seem to participate in producing what Callon has termed 'overflow' (Callon, 1998b), or in the language of economics, the 'market failure' it self. Such overflow, I will argue, is not simply produced by accident or chance, but as a consequence of the costly activity of framing technology conveniently - as pure and protected all a long. But then again, even if economists are operating with convenient frames (recall that this is what neoclassical economists them selves seem to claim), it is necessary to add other entities to account for the very production of such convenient frames. Far from being the masters and engineers of convenient frames, economists seem to be mastered by them. Indeed, convenient frames seem to be made up of 
heterogeneous elements consisting of both humans and non-humans of which economists are but one such element:

The first section of this paper described the peculiar division of labor between engineers and neoclassical economists in the production of the pure technological relations of the Other production function. Convenient frames also make neoclassical economists quite similar to the engineering scientists in the FMS case. Yet, there is one significant difference. The latter seems to operate with a more durable version of the 'technical law', embodied as it is into the very machinery made of steel. This allows engineering scientists to continue the work of purification at a point in which computer-based simulations and textbook calculations stops short, that is, at the multiple points of design, selection, purchase, use and evaluation. Machinery made of steel seems to travel a longer distance - those humans associated with it, such as engineers, are allowed to travel longer than economists.

This difference in performance between the two sciences, it is further suggested here, is closely associated with differences in material associations. Tobin (1967) has already made an important point in this respect, at the now well-known conference among eminent economists: "One reason for two-factor aggregation is that blackboards are two-dimensional" (p.51). Economics textbooks are also two dimensional, yet confined to the world of written texts. Computer-based simulation and calculation do alter these things - the association extends and grows stronger by adding computer power to textbooks and two-dimensional black boards. With such materials, it becomes possible to make a difference in a simulated world of IF-THEN. Such are the materials making up the world of technology-policy. These are still fragile materials in a manufacturing world of caste iron and steel. It is only through adding an even stronger association with materials made of steel that such a simulated world of almost existing possibilities can make the transformation into a manufacturing world to be 'found in practice'. The outcome of this transformation is a given state of technical knowledge, in this case, the FMS that in principle cannot be a failure in world of simulations nor in a world to be 'found in practice'. The neoclassical response "It can not be what must not be" is to the point in describing such a world in which a given state of technical knowledge is reproduced. Computer-based calculation and simulation traveled far. In association with computer-based FMS they could both travel further. This state of affairs may also explain why economics have made the 'ruling' technology and the 'technical law' so central to its own science so as to make it into their 
'hard core'. But then again, such convenient frames are neither limited to neoclassical economics, nor to humans, but is vastly extended through heterogeneous materials.

Adding such heterogeneous materials like steel and computer based calculation tools to homo economicus produce a new emerging hybrid creature. I will call this emerging creature 'engineering-economicus' to emphasize the heterogeneous materials it is made of (recall that we are not just dealing with humans among themselves), consisting both of the materials making engineering science as well as the materials performing economics. Hybrid creatures such as engineering-economicus, solves both the problem of technical maximization as well as that of economic optimization, while simultaneously achieving and maintaining pure technological relations - as if being a fully fledged homo economicus. It is this re-made homo economicus that is capable of traveling all the way from micro-to-macro while transforming society through its multiple purifications, reproducing a given state of technical knowledge: "It can not be what must not be".

The perfect and pure knowledge of homo economicus would be compromised beyond recognition if this creature was to be confronted with anything else but perfectly purified technology to select from when solving the twin problems of technical maximization and economic optimization. Once again, Brown (1968) and other eminent economists have already reached the correct conclusion in this respect " ...the ruling technology sets the conditions..." (Ibid., p. 2). Without the purifications of technological relations, 'homo economicus' it self will simply cease to exist. Hence, 'Homo economicus' is not just a foundation in Economics, but an outcome from a process of purification, in which the separation, between exogenous and endogenous, between technology and firms, between technology and markets, between technology and humans, between materials and knowledge, and ultimately the separation between the Natural and the Political is produced. Heterogeneous 'Engineering-economicus' summarize what is at stake and what it takes, to produce homogeneous homo economicus, that is, a dematerialised decontextualized entity deprived of all relations to the materials.

Yet, it would be to miss the point entirely, if such an outcome - 'homo economicus' it self, is regarded as a 'culture free' entity as so strongly argued by the new economic sociologists. Instead of arguing for further cultural exclusion, the boundary of the research task should be drawn in a more generous way. Homo economicus should be regarded, not as an alien entity, but as a cultural 
product worthy of an anthropological investigation. As Traweek (1988) has already described, a cold "culture of no culture" emerged from the world of energy physics. Haraway (1996) has described how a masculine culture of no culture emerged from the particular way experimental science was staged in Boyle's laboratory in the 1650s and 1660s. Pure experimental science emerged through the exclusion of the female body - only males were granted the objective gaze necessary for its production. I would like to suggest that famous homo economicus can be one of those figures participating in the production of the culture of no culture, in research and practice alike - as yet another type specimen " of modern heroic, masculine action - of the mind" (Haraway, 1996, p.435). Such an anthropological feminist inspired suggestion would be difficult to articulate, not to say investigate, as long as homo economicus is excluded from 'culture'. To reconstruct and register those events bringing this creature into existence, can perhaps be considered as one of the relevant tasks to attend to along this line of inquiry.

As a way of summarizing, I would like to propose an anthropology of natural and political markets, while comparing it with the alternatives:

The market can perform as if an almost natural law - securing the optimal efficiency in the allocation of scarce resources. This is by now a well-known proposition in neoclassical economics. The proposition assumes that market transactions and the allocation of scarce resources take place under conditions of perfect knowledge. The given 'technical knowledge' of the pure neoclassical production function is just but one particular instance of this general proposition. Knowledge is thus taken for granted. The new economic sociologists propose to replace what they regard as the 'culture free' perfect knowledge of homo economicus with the socially constructed knowledge of homo sociologicus. With the advent of the knowledge based economy, or simply 'the new economy', knowledge it self has been topicalized as a scarce resource - as something that cannot be taken for granted. Certainty is now replaced with uncertainty. Knowledge can no longer simply be viewed as premises in an explanation of the performance of the market institution. Yet knowledge in the new knowledge economy is considered to be abstract and dematerialized as 'mental models' or 'cognitions', that can be shared among humans or located inside the individual human's head (e.g. Nonaka, Takeuchi, Umemoto 1996, Drucker 1993).

The neoclassical economists proposed a given knowledge to be both a premises and outcome of market transactions. Those authoring the advent of the new knowledge economy proposed 
dematerialized knowledge, while allowing for more uncertainty - in a way not so different from the new economic sociology. I would like to propose yet another alternative:

The notion of political markets proposed here suggests that 'Natural' markets are just but one special case of political markets. Natural markets are an exception, indeed an exceptionally highly organized and costly outcome from a process of technological purification in which uncertainties are systematically eliminated. Natural markets is not a rule, but is ruled by its master, the perfectly purified technological relations: The 'pure technological relations', the 'ruling technology' (Brown, 1968) the 'given technical knowledge' - the 'technical law' it self (Samulesson 1980), is a necessary condition for the existence of the Natural market as well as for homo economicus it self. Purified technological relations - not 'homo economicus', is the ruling master producing the necessary conditions for the existence of the Natural market. Conversely, it is suggested here that 'market failures' and associated impurities is the rule - not the exception, under normal conditions. These are the conditions in which uncertainties emerge - in the FMS case, when 'self-evident' technologies transform into the less certain and less pure technologies to be renegotiated and discarded. Thus, the notion of political markets proposed here, holds the view that a given technical knowledge is a temporary outcome from work of purifications. The temporality, as can be seen, made its presence through the very material associations. Initially, FMS passed through various configurations; simplified as 'new technology' so as to become part of a computer based calculation of technical change linking micro-to macro, as written texts in the governmental investigation, as plastic bricks at a design meeting, as plywood at an exhibition, as drawings on a piece of paper at a technical advisory board, as a written investment calculus, as computer integrated machinery made of steel at the factory - without becoming negotiated and less pure. Then FMS started to disintegrate and become less pure as the automatic quality measurement robot was disconnected, as more and more humans were added to the almost perfectly automated machinery - only to be reconfigured once more as it was finally sold as individual items on the market for second hand machines. Together with the humans on the factory floor, those machines scheduled for replacement made the day. The humans interacting with these heterogeneous materials were not unaffected. Initially they were framed as they went along with the inscriptions of the master FMS. Then the FMS went through a process of reconfigurations, reframing and redefining both the master inscription and the humans at the factory floor. Both processes of framing and reframing co-exists the latter being part and parcel of the unexpected overflow in the form of transformed technical knowledge: The 'self-evident' and almost irreversible master inscription slowly transformed into 
the less certain and reversible technologies to be sold on the market for second hand machines. Hence, what was 'self-evident' knowledge regarding what technologies to introduce and what to discard, became radically transformed as events unfolded. As a byproduct of such normal conditions in which knowledge transforms and translates into uncertain technologies and market failures - new equally normal markets emerge, for second hand technologies.

Last but not least, under such normal market conditions, some sense of particular identity between the producer, the product and the price is regained once again. The general price once achieved and inscribed into the written investment calculus that traveled all the way up to the corporate board, was again turned back into a price with a particular sense of identity. The now emerging second hand CNC-machines were priced at approximately 200.000-300.000 SEK each by one of the engineers in the company. He considered that as a 'normal price' (!) for such second hand machinery. Then they were sold so as make a beautiful (albeit provisional) end of this case -as well as a beautiful return of the investment - and of technology transfer, back to the Swedish machine tool producer that almost a decade earlier had figured as the sovereign supplier of the master FMS. Also the particular identity of the customer and supplier became slightly reshuffled and reversed as part of this remaking of natural markets into normal ones.

Thus the notion of political markets proposed here suggests that knowledge can be both premises as well as an outcome of market transaction - as knowledge, its status and distribution can be (re) negotiated in the process. The given 'technical knowledge' being no exception. Hence, when market transaction takes place, knowledge it self can be transformed, and with it, the conditions for conducting the market transaction. So, it is proposed here that knowledge is not just transformed through human interaction as suggested by the New economic sociologists and the proponents of the New economy, but transformed through the kinds of material inscriptions and associations just referred to above.

The proposed significance of material inscriptions and associations for the production and transformation of knowledge should not be seen as a critique of the neoclassical theory of the firm, but as a constructive contribution. Far from claiming a 'crisis' in the theory of the firm, it has been argued through out this paper, that neoclassical economics has participated in the successful purification of technological relations. Yet, in order to provide for an explanation of such a successful outcome, it is not enough to account for economists among themselves. Also calculations 
and associated material inscriptions of various sorts, e.g. the computer-based simulation of the macro-economy, the written investment calculus, the engineering scientists drawings and their plastic bricks, must be brought into such an explanation, as already argued by Callon (1998a, 1998b, 1991). In more specific terms, the puzzling 'residual' in the neoclassical production function can be explained by now also taking into account the many subtle ways economics itself interfere in making up the residual. Economics only have to refine their production function so as to account for the significance of such material inscriptions and associations. Done properly, a revised macroeconomic model would emerge, capable of handling failures in different ways. For example, instead of attributing all failures to the market and no failures to technology, a more symmetric distribution of failures between the two entities would be allowed for. Further more, each time a 'residual' emerge from applying the revised model, it is no longer simply due to 'technical change' but also due to 'market failures'. Hence, such a revised macro-economic model not only allow economics to maintain the distinction between technology and the market, but also allows for the flexibility of including those excluded, that is, the material inscriptions and associations participating in making up the distinctions between the two. 


\section{REFERENCES}

Abramovitz, M. Resource and Output Trends in the United States Since 1870. Papers and

Proceedings of the American Economic Association, vol.46 (May 1956), pp. 5-23.

Augier, M. and Kreiner, K. Rationality, Imagination and Intelligence: Some Boundaries in Human Decision-making. Industry and Corporate Change, Vol. 9 Nr. 4 (2000), pp. 659-681).

Brown, M. Introduction. In: M. Brown (ed.) The Theory and Empirical Analysis of Production. Studies in Income and Wealth, Volume 31, pp. 3-13(New York: National Bureau of Economic Research, 1967).

Brown, M. On the Theory and Measurement of Technological Change (Cambridge: Cambridge University Press, 1968).

Callon, M. 1986. Some Elements of A Sociology of Translation: Domestication of The Scallops And The Fishermen of St Brieuc Bay. In J. Law (Ed.), Power, Action and Belief: A New Sociology of Knowledge? :196-233. London: Routledge \& Kegan Paul.

Callon, M. 1991. Techno-economic networks and irreversibility. In: J. Law (ed.) A sociology Monsters: Essays on Power, Technology and Domination. London: Routledge, pp. 132-161.

Callon, M. 1998a. The Embeddedness of Economic Markets in Economics. In: M. Callon (ed.) The Laws of the Markets (Oxford: Blackwell Publishers/The Sociological Review), pp. 1-57.

Callon, M. 1998b. An essay on framing and overflowing: economic externalities revisited by sociology. In: M. Callon (ed.) The Laws of the Markets (Oxford: Blackwell Publishers/The Sociological Review), pp. 244-269.

Callon, M., Méadel, C. and Rabeharisoa, V. 2002 The economy of qualities. Economy and Society Vol. 31 Nr. 2 , pp. 194-217.

Carlsson, B. \& Olavi, G. Technical change and longevity of capital in a Swedish simulation model. In G. Eliasson (ed.)A Micro-to-Macro Model of the Swedish Economy. Papers on the Swedish Model from the Symposium on Micro Simulation Methods in Stockholm Sept. 19-22, 1977, pp. 127136. IUI Conference Reports 1978:1 (Stockholm: Almqvist\&Wiksell International, 1978).

Carlsson,B. (ed.), Technological Systems and Economic Performance: The Case of Factory Automation (Dordrecht: Kluwer Academic Publishers, Economics of Science, Technology and Innovation series volume 5, 1995).

Chung, J. W. Utility and Production Functions: Theory and Applications (Oxford: Blackwell, 1994).

Coombs, R., Saviotti, P. and Walsh, V. Economics and Technological Change (London: Macmillan Education, 1987)

Cyert, R. \& March, J., A behavioral Theory of the Firm (Englewood Cliffs, NJ: Prentice-Hall 1963). 
Czarniawska, B., Identity lost or Identity Found? In: M. Schultz, M. J. Hatch \& M. H. Larsen (Eds.), The Expressive Organization: Linking Identity, Reputation, and the Corporate Brand (New York: Oxford University Press, 2000), pp. 271-283.

Czarniawska, B. \& Sevón, G. (Eds.), Translating Organizational Change (Berlin, New York: Walter de Gruyter, 1996).

Drucker, P., Post-capitalist Society (Oxford: Butterworth-Heineman Ltd. Linacre House, Jordan Hill, 1993).

Eliasson, G., Presentation of the Swedish Micro-to-Macro Model. In G. Eliasson (ed.)A Micro-toMacro Model of the Swedish Economy. Papers on the Swedish Model from the Symposium on Micro Simulation Methods in Stockholm Sept. 19-22, 1977, pp. 3-83. IUI Conference Reports 1978:1 (Stockholm: Almqvist\&Wiksell International, 1978).

Eliasson, G., The Firm and Financial Markets in the Swedish Micro-to-Macro Model - Theory, Model and Verification (Stockholm:Almqvist\&Wiksell International, 1985).

Guesnerie, R., La économie de marché. (Dominos, Paris: Flammarion, 1996).

Haraway, D., Modest Witness: Feminst Diffractions in Science Studies. I: P. Galison and D.J. Stump (eds.) The Disunity of Science: Boundaries, Contexts, and Power (Stanford, California: Standford University Press, 1996).

Heathfield, D.F. and Wibe, S. Introduction to Cost and Production functions (Basingstoke: Macmillan Education, 1987).

Hirsch, P., Michaels, S., Friedman, R. Clean models vs. dirty hands: Why economics is different from sociology. In: S. Zukin, S. and P. DiMaggio (eds.) Structures of Capital: The Social Organization of The Economy (Cambridge: Cambridge University Press, 1990), pp. 39-56.

Karnøe, P. Dansk Vindmølleindustri - en overraskende international success. (Copenhagen: Samfundslitteratur, 1991).

Kreiner, K. \& Tryggestad, K. The Co-production of Chip and Society: Unpacking Packaged Knowledge, Scandinavian Journal of Management, Vol. 18 (2002), pp. 421-449.

Kurz, M., and Manne, A.S. Engineering Estimates of Capital-Labor Substitution in Metal Machinery, American Economic Review, 53 (1963), pp. 662-681.

Kurz, H. D. and Salvadori, N. Production Theory: A Long-Period Analysis. (Cambridge: Cambridge University Press, 1995).

Latour, B. Science in Action (Cambridge, Mass: Harvard University Press, 1987).

Latour, B. We Have Never Been Modern (Cambridge, Mass: Harvard University Press, 1994). 
Law, J. Technology and Heterogeneous Engineering: The Case of the Portuguese Expansion. In W.E. Bijker, T.P. Hughes \& T.J. Pinch (Eds.) The Social Construction of Technological Systems (Cambridge, Mass: The MIT Press: 11-34, 1987/1990.)

March, J. Bounded rationality, ambiguity, and the engineering of choice. Bell Journal of Economics, Vol. 9 (1978), pp. 587-608.

March, J. A Primer in Decision Making (New York: Free Press, 1994).

Mill. J.S. Principles of Political Economy with Some of Their Applications to Social Philosophy, $1^{\text {st }}$ edn 1848, edited by J. M. Robson. ( Toronto: University of Toronto Press, 1965).

Nelson, R.R. \& Winter, S.G. 1982. An Evolutionary Theory of Economic Change. Cambridge, Massachusetts: Belknap Press of the Harvard University Press.

Nonaka, I., Takeuchi, H. and Umemoto, K. A theory of Organizational Knowledge Creation. International Journal of Technology Management, Vol. 11, No. 7/8 (1996) pp. 833-845.

OECD, Government Policies and the Diffusion of Microelectronics (Paris: OECD, 1989).

Pinch, T.J. and Bijker, W.E. (1987), "The social construction of facts and artifacts: Or How the Sociology of Science and the Sociology of Technology Might Benefit Each Other". In: W.E. Bijker et al., The Social Construction of Technical Systems.(Cambridge, MA: MIT Press. pp. 19-50).

Proposition 1983/84: 135. Stockholm: offentlig tryck.

Robinson, J. Collected Economic Papers. Euler's Theorem and The Problem of Distribution, pp.119 (Oxford: Basil Blackwell, 1951, Reprinted from Economic Journal, 1934).

Rosenberg, N. Inside the Black Box: Technology and Economics (Cambridge: Cambridge University Press, 1982).

Salter, W.E.G. Productivity and Technical Change (Cambridge: Cambridge University Press, 1960, Second edition 1966).

Samuelson, P.A., Foundations of Economic Analysis (Cambridge: Harvard University Press, 1947)

Samuelson, P.A. Economics, eleventh edition (Auckland:McGraw-Hill, 1980).

Samuelson, P.A., Nordhaus, W.D. Economics, seventeenth edition (Boston: McGraw-Hill, 2001).

Shephard, R.W. Theory of Cost and Production functions ( Princeton, New Jersey: Princeton University Press 1953/1970).

Smith, A. The Wealth of Nations, Books I-III. London: Penguin Books (1776/1986).

Solow, R. Technical Change and the Aggregate Production Function, The Review of Economics and Statistics, vol. 39 (August 1957), pp.312-320. 
Solow, R. Some Recent Developments in the Theory of Production. In: M. Brown (ed.) The Theory and Empirical Analysis of Production. Studies in Income and Wealth, Volume 31, pp. 25-50 (New York: National Bureau of Economic Research, 1967).

SOU, Datateknik i industriproduktionen. Förslag till industripolitiska åtgärder. Betänkande av data- och elektronikkommittén, DEK (Stockholm: Liber Förlag, 1981:59).

Tobin, J. Comment (On Solow's paper: Some Recent Developments in the Theory of Production). In: M. Brown (ed.) The Theory and Empirical Analysis of Production. Studies in Income and Wealth, Volume 31, pp. 50-53 (New York: National Bureau of Economic Research, 1967).

Traweek, S., Beamtimes and Lifetimes (Cambridge, Mass.: Harvard University Press, 1988)

Tryggestad, K. Teknologistrategier og postModerne Kapitalisme: Introduksjon av computerbasert produksjonsteknikk. (Eng. Technology Strategies and postModern Capitalism: The Introduction of Computer Based Production Techniques, Ph.D., pp. 1-432 Lund: Lund University Press, 1995).

Zukin, S. and DiMaggio, P. Introduction. In: S. Zukin, S. and P. DiMaggio (eds.) Structures of Capital: The Social Organization of The Economy (Cambridge: Cambridge University Press, 1990), pp. 1-36.

Österberg, D. Metasociology: An Inquiry into the Origins and Validity of Social Thought (Oslo: Nowegain University Press, 1989).

\footnotetext{
${ }^{1}$ See also Callon (1991) for an earlier elaboration on the role and significance of inscriptions and associated materials

${ }^{2}$ The new economic sociology is of course not the first one to elevate critique against (neo)classical economics and associated assumptions regarding homo economicus and the firm. I will not attempt to review it all, but refer the interested reader further: For an introduction and summary of the critique pertaining to the theory of the firm and production, see Coombs, Saviotti and Walsh (1987) and Karnøe (1991). For a more detailed treatment of the same subject, see also Rosenberg (1982). As further suggested by Österberg (1989), it is possible to write up a whole history of sociology and social thought as a critique against (neo)classical economics. Less critical and more constructive are the seminal work of Cyert and March (1963) and their process (behavioral) theory of the firm. The authors, coming from an emerging tradition within organization theory, extended H. Simon's notion of bounded rationality to the collective - the firm, while describing it as a nexus of coalition building. The dynamic process of coalition building is further more capable of trespassing firm boundaries and associated neoclassical distinctions between what is exogenous and what is endogenous to the firm, e.g. by including suppliers and associated factor markets in the coalition building. Evolutionary economics is yet another emerging tradition, basically criticizing neoclassical economics from within the discipline, notably on assumptions regarding economic optimization (or rational profit maximizing behavior) and static equilibrium conditions. Although drawing upon the notion of bounded rationality, prominent representatives of evolutionary economics do not seem to pay so much attention to the dynamics described by Cyert and March (1963). Coalition building and trespassing of firm boundaries into factor markets seems not to be part of the evolutionary dynamics. Instead, a basic distinction in neoclassical economics, i.e., between exogenous and endogenous firm conditions is reinforced, in which suppliers and associated factor markets for technology is made into exogenous entities: "The core concern of evolutionary theory is with the dynamic process by which behavior patterns and market outcomes are jointly determined over time. The typical logic of these evolutionary processes is as follows: At each point of time, the current operating characteristics of firms, and the magnitudes of their capital stocks and other state variables, determine input and output levels. Together with market supply and demand conditions that are exogenous to the firm in question, these firm decisions determine market prices of inputs and outputs. The profitability of each individual firm is thus determined. (Nelson and Winter 1982, pp. 18-19).

${ }^{3}$ As indicated above, the more complex production function associated with engineers would also implicate a spatial dimension, and hence yet another classical factor of production - land.
} 


\footnotetext{
${ }^{4}$ Solow's aggregate production function is mathematically represented by the following equation in which; Q represents output and K and L represents input of "physical" (ibid., p.312) units of capital and labor respectively, so that: $\mathrm{Q}=$ $\mathrm{F}\left(\mathrm{K}, \mathrm{L},{ }^{*} \mathrm{t}\right)$. Last, but not least, the variable representing the residual 'technical change': "The variable $t$ for time appears in $\mathrm{F}$ to allow for technical change." (Ibid. My emphasis).

${ }^{5}$ In a very literal way Brown's expression 'the ruling technology' nicely summarize what neo classical economists have recognized for long: that the existence of pure technological relations is a necessary condition for a solution to the problem of economic optimization.

${ }^{6}$ All verbal quotations are translated from Swedish by the present author. Company names are fictious. Other quotations from published sources are fully referenced in the list of references at the end.

${ }^{7}$ This fitting into actual aggregate 'macro' statistics (e.g. annually produced industry trend statistics) is also among the most important "Master criteria for fit" (Eliasson, 1978, p. 220) in the model. When calibrating the model, the firms allowing for the aggregation were made into synthetic ones: " To get a micro data set at an early time we had to be satisfied with synthetic data. Until spring 1977 macro sub-industry data for 1970-74 (four subindustries) have simply been chopped up into 50 firms..." (Ibid., 223. My emphasis). In later and more refined versions of the model, the database making up the 'micro' now includes not only the 'synthetic' firms but 'real' ones as well (see also Carlsson et al.1995).

${ }^{8}$ Here, it should be noted that the simulation model does not incorporate a strong neoclassical assumption of a global solution to the problem of economic optimization, but is confined with one that is satisfying according to a predefined state in a vein similar to what Samuelson (1947) calls 'state dependent' models. Instead of a strong assumption ex-ante, a global solution represented by a 'dynamic equilibrium' (one that converges more or less towards a global optimum) can be reached ex-post, either by chance or through policy intervention as in "Neoclassical interest rate policies and Schumpeterian policies aimed at stimulating the faster dissemination of improved technology through the investment process...(Eliasson, 1985, p.404. Author's own emphasis. For more detailed accounts of the model, see also Carlsson and Olavi 1978, Eliasson 1978, Carlsson et al. 1995).

${ }^{99}$ Quoted from Kurz and Salvadori (1995, p.449) when describing the 'defense of traditional neoclassical theory'.

${ }^{10}$ Here, it seems that the 'Social construction of technology' (Pinch and Bijker, 1987) have dismissed the relevance of the linear innovation-diffusion model a little bit too hastily.

${ }^{11}$ The economist once participating in the CEC investigation articulated the following view during one of our conversations some ten years later; that the simplifications of technology associated with current economic simulation models may actually add major costs to firms when they are turned into policy-making - without paying sufficient attention to actual firms and associated markets and technologies. This is an important and valuable insight, which has much in common with the argument of 'convenient frames', pursued here.
} 